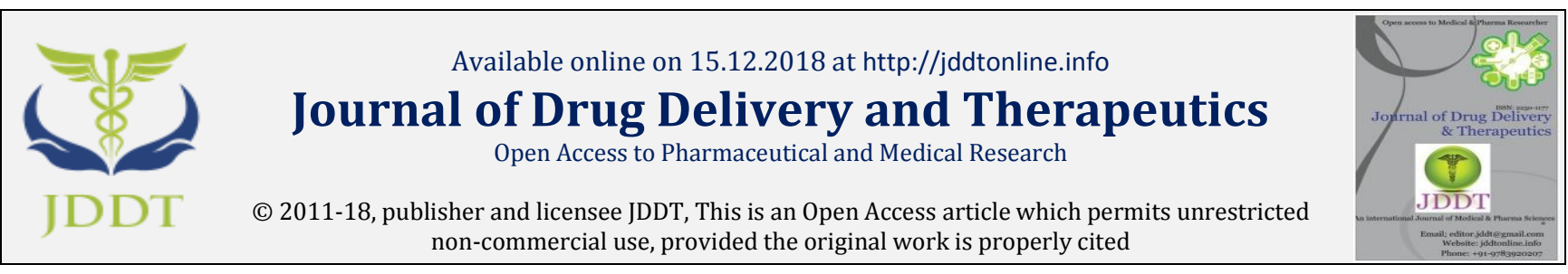

Open $\odot$ Access

Review Article

\title{
Microparticulate hot melt pallets technology: a review
}

\author{
Shekhar Kokate *, Dr. Punit R Rachh ${ }^{2}$ \\ Department of Pharmacy, Bhagwant University, Sikar Road, Ajmer, Rajasthan. India
}

\begin{abstract}
Recent advances in novel drug delivery (NDDS) aims to enhance safety and efficacy of drug molecule by formulating a convenient dosage form for ease of administration and to achieve better patient compliance. Depending upon functionality, it is possible to design different dosages forms which fulfill the therapeutic needs of the patient with improved bioavailability of poorly water soluble drugs, taste masking and preparation of oral dispersible tablets, MUPS and multiple unit formulations. The hot-melt technology is one of the most commonly used method, is devoid of solvent use, solvent disposal, solvent evaporation and solvent treatment is not required.
\end{abstract}

Keywords: Multiple Unit Pallet Systems, Lipid, Solubility, Hot-Melt Technology, Bioavailability, Absorption of Drug.

Article Info: Received 28 Oct, 2018; Review Completed 08 Dec 2018; Accepted 10 Dec 2018; Available online 15 Dec 2018

\section{Cite this article as:}

Kokate S, Rachh PR, Microparticulate hot melt pallets technology: a review, Journal of Drug Delivery and Therapeutics. 2018; 8(6-s):377-383 DOI: http://dx.doi.org/10.22270/jddt.v8i6-s.2131

\section{*Address for Correspondence:}

Shekhar Kokate, Department of Pharmacy, Bhagwant University, Sikar Road, Ajmer, Rajasthan. India

\section{INTRODUCTION}

A dosage form is a drug delivery systems designed to deliver the active ingredient(s) to the body. It must produce the same therapeutic response each time it is administered. The most common and popular route for administration of a dosage form or drug delivery system is oral. Amongst the various drug formulations or delivery systems for oral administration, the solid dosage forms are most widely used and produced. Tablets and capsules are two of the most predominant solid oral dosage forms. ${ }^{1}$

The use of hot-melt extrusion (HME) within the pharmaceutical industry is steadily increasing, due to its proven ability to efficiently manufacture novel products. The process has been utilized readily in the plastics industry for over a century and has been used to manufacture medical devices for several decades. The development of novel drugs with poor solubility and bioavailability brought the application of HME into the realm of drug-delivery systems. This has specifically been shown in the development of drugdelivery systems of both solid dosage forms and transdermal patches. HME involves the application of heat, pressure and agitation through an extrusion channel to mix materials together, and subsequently forcing them out through a die. Twin-screw extruders are most popular in solid dosage form development as it imparts both dispersive and distributive mixing. It blends materials while also imparting high shear to break-up particles and disperse them. HME extrusion has been shown to molecularly disperse poorly soluble drugs in a polymer carrier, increasing dissolution rates and bioavailability. The most common difficulty encountered in producing such dispersions is stabilization of amorphous drugs, which prevents them from recrystallization during storage. Pharmaceutical industrial suppliers, of both materials and equipment, have increased their development of equipment and chemicals for specific use with HME. Clearly, HME has been identified as an important and significant process to further enhance drug solubility and solid-dispersion production..$^{5-6}$

Hot-melt extrusion (HME) processing were come in action in the early 1930s, and during that time, and became the most widely applied processing technology in the plastic, rubber, and food industries. The application of HME expanded to the pharmaceutical industry at the beginning of the seventies for formulation and product development as well as manufacturing. The first application of HME as a manufacturing tool in the pharmaceutical industry was investigated by El-Egakey. ${ }^{1}$ using poly (vinyl acetate-comethacrylic acid) and epoxy resin containing a secondary amine as a polymeric carrier ${ }^{1}$. HME includes a continuous process of pumping polymeric materials in a rotating screw temperatures usually above their glass transition temperature (Tg) and often at temperature above the melting point to achieve molecular level mixing of the active compounds and binders ${ }^{2-3}$ resulting into an amorphous product with a uniform shape and density, with improved dissolution profile of the poorly water-soluble drug ${ }^{4}$. HME technology having several advantages over conventional pharmaceutical manufacturing processes such as shorter and more efficient time to achieve the final product, ecofriendly due to the elimination of solvent use, and increased efficiency of drug delivery to the patient. As a result, HME has emerged as an alternative platform technology to other traditional techniques for manufacturing pharmaceutical dosage forms such as tablets, capsules, films, and implants for drug delivery via oral, transdermal, and transmucosal routes. The introduction of HME to pharmaceutical formulation development has made 
sophisticated equipment such as the extruder, customized downstream auxiliary equipment, and monitoring tools available for application in evaluating the performance and product quality. To date, several research articles have been published describing the use of HME as the novel technique of choice in dealing with the day-to-day formulation challenges of new active pharmaceutical ingredients (APIs). Moreover, numerous aspects of the HME technology have been extensively cited in the literature. Additionally, the number of patents based on HME techniques has risen steadily worldwide in recent decades. . $^{4-13}$

\section{Hot-melt technology}

Hot-melt technology is a process in which molten excipient(s) and/or drug are either layered on substrate, congealed alone or with excipient(s) using one of the following processes to design to improved drug delivery systems -

a) Hot-melt coating

b) Spray congealing

c) Hot-melt extrusion and spheronization

d) Hot-melt extrusion

e) Hot-melt granulation.

Hot-melt coating: Hot-melt coating involves spraying of molten excipient(s) or mixture of molten excipient(s) and drugs either in suspended or dissolved form onto a substrate during fluidization in a fluid-bed coating device leading to solidification of the substrate on cooling and form a thin homogenous film. ${ }^{16}$

Spray congealing: Spray congealing is a method of converting molten excipient(s) with drug into dry powder, granules or spheroids by spraying through suitable pneumatic nozzles in a stream of co-current or countercurrent cold fluidized air. ${ }^{17}$

Hot-melt extrusion and spheronization: Hot extrusion spheronization is a multiple step process. The process involves hot-melt extrusion of low melting point excipient(s) with drug followed by hot-melt spheronization and gradual cooling during spheronization to produce uniform size spherical congealed particles, called as spheroids, pellets, beads or matrix pellets. ${ }^{18}$

Hot-melt extrusion: Hot-melt extrusion is the process of converting a uniform mixture of excipient(s) and drug into a product of uniform shape and density by forcing it through a die under controlled conditions of temperature to convert the molten clear mass into solid mass. ${ }^{19}$

Hot-melt granulation: Hot-melt granulation is the process of formation of agglomerates of mixture of excipient(s) and active pharmaceutical ingredient(s) using molten mass as binder under high shear mixing. ${ }^{20}$

\section{Key Points of Hot-Melt Technology}

The various advantages of hot-melt technology in drug delivery are listed below: 17

1. Neither solvent(s) nor water is used in the process.

2. Fewer processing steps are needed, thus shorter processing times.

3. Fewer processing steps, thus less critical process parameters.

4. Good stability at varying $\mathrm{pH}$ and moisture levels.

5. Used for improved drug delivery.

6. Overall low production cost.

7. Since organic solvents are avoided, the process is environment friendly as well as safe for personnel and facility where processing is done.

\section{Limitations of Hot-Melt Technology}

The various demerits of hot-melt technology in formulation design are as under:

1. Requires high energy input.

2. Cannot be applied to heat-sensitive materials.

3. Specially designed equipment's are required.

4. Limited lipid excipients and thus limitations in formulation design.

\section{Application of hot melt Technology}

Lipid-Based systems for Bio enhancement: Bioavailability ${ }^{18}$ refers to the rate and extent of the drug absorption in the systemic circulation after administration by a given route. For oral administration, bioavailability of drugs depends on solubility of the drug in the gastrointestinal fluid along with permeability of drug which governs the dissolved drug absorption into the gastrointestinal membrane.

Taste Masking: Taste is one of the most important parameter governing patient compliance. Oral administration of bitter drugs with an acceptable degree of palatability is a key issue for health care providers, especially for pediatric patients. Use of flavor/sweetener and physical/chemical methods to prevent the drug substances from interaction with the taste buds are the two approaches of masking the nauseous or bitter taste of the medicaments. The major disadvantage of physical method of the taste masking by polymer require organic solvents to dissolve the polymer and difficult processbility for example, solvent evaporation, organic phase separation methods, etc. One of the best physical approaches to mask the drug taste is by the spray congealing technique, ${ }^{21}$ the microspheres of drug entrapped in lipids, prepared by spray congealing, mask the bitter taste of the drug and improve palatability. ${ }^{22}$

Multiple-Unit Formulations: Multiple unit formulation such as pellets is widely employed for modified release dosage forms. The conventional means for manufacturing these dosages forms include drug layering or extrusionspheronization followed by functional coating. The drug release is controlled by varying the thickness of the coating and chemical nature of polymers. ${ }^{23}$ Traditionally polymers were dissolved in a solvent (water or organic) prior to spraying. During and after coating the solvent must be evaporated. The use of solvents nowadays is under constraint due to the residual solvent in traces levels, while recovering a solvent often proves expensive. Due to long evaporation time water could also be a problem. In order to avoid such problems and to reduce costs. A better alternative is pellets prepared by the spray congealing which is a single step process that provides drug particles embedded in the matrix of the wax so that drug release occurs by diffusion and erosion mechanism. To control drug release it is appealing to use a wax of different lyophilicity as coating materials. Waxes of varying lyophilicity are available and can be used to regulate the customized drug release from multiunit controlled release pellets. The application of saturated polyglycolized glyceride (Gelucire ${ }^{\circledR}$ 50/02) and glycerol palmitostearate (Precirol ${ }^{\circledR}$ ATO5) as drug release regulators for propranolol Hydrochloride pellets. ${ }^{22-25}$

Multiple-Unit Pellet System (MUPS): In pharmaceutical industry and research perspective, the term in general refers to MUPS compacted into tablets. Thus, the resulting tablets prepared by compaction of modified release coated multiparticulates or pellets are called as MUPS. ${ }^{23}$

It is recognized that oral administration of a multi-unit controlled release dosage form is preferred over single 
dosage unit due reduction in inter- and intra-subject variability in drug absorption and clinical response. The number of micropellets per MUPS dosage form is much more therefore possibility of dose dumping (in stomach) and incomplete drug release is further minimized. A particular problem occurs if the micropellets coated with a polymer. Polymer film which controlled drug release, as the tableting process can cause severe damage to the film altering the release characteristics from the micropellets. The compaction of micropellets requires special efforts. The hotmelt technology offers the matrix micropellets having ideal characteristics for compaction i.e. retarding drug release in GI fluid while providing cushion during pellet compaction. ${ }^{24-}$ 27

Melt Granulation: The granules for modified release or conventional release tablets can also be manufactured by the hot-melt technology. The fluid hot-melt granulations for the preparation of granules for tableting. ${ }^{24}$ Melt granulation are also used for low dose modified release tablet. It eliminates the milling and sifting step during tablet manufacturing. ${ }^{28}$

\section{Excipient for Hot Melt Technology:}

Lipids are defined as amphiphilic molecules which are naturally occurring and semisynthetic molecules in nature include fatty acid, fatty alcohol, wax and phospholipids etc. The amphiphilic nature of some lipids allows them to form structures such as micelles, vesicles and liposomes etc. in an aqueous environment.18

Fatty Acids: A fatty acid ${ }^{29}$ is a carboxylic acid with a long unbranched aliphatic chain which is either saturated or unsaturated.

i) Saturated fatty acids

ii) Unsaturated fatty acids

\section{Fatty Alcohols}

Fatty alcohols ${ }^{30}$ are aliphatic alcohols consisting of a chain of 8 to 22 carbon atoms. Fatty alcohols usually have even number of carbon atoms and a single alcohol group $(-\mathrm{OH})$ attached to the terminal carbon.

Glycerolipids: Glycerolipids are composed mainly of mono-, di-, and tri-substituted glycerol's. Thus glycerolipids are glycerol ester of the fatty acid and fabricating by incorporating the functional moiety to modify physicochemical properties. Depending upon substitution of the hydroxyl group of the glycerol by fatty acid they are as monoglycerides, diglycerides and triglycerides.

Waxes and Oils: Waxes are organic compounds that characteristically consist of a long alkyl chains. Natural waxes are typically esters of fatty acids and long chain alcohols. Synthetic waxes are long-chain hydrocarbons lacking functional groups. ${ }^{32}$

Phospholipids: Phospholipids are a class of lipids and are a major component of all cell membranes as they can form lipid bilayer. Most phospholipids contain diglycerides, a phosphate group and a simple organic molecule such as choline, lecithin (phosphatidyl choline). ${ }^{18}$

Surfactants: A surfactant is organic compound which has both hydrophilic and hydrophobic portions which reduces surface tension between two immiscible liquid which facilitate the immersion or dispersion of the one phase into another phase. Surfactant classified according to the composition of their head: anionic, cationic, amphoteric and non-ionic. 33

\section{Non-Lipidic Excipients}

Butylated hydroxyanisole: Butylated hydroxyanisole is an antioxidant with some antimicrobial properties. ${ }^{34-35}$ It is used in a wide range of cosmetics, foods and pharmaceuticals having melting point $47^{\circ} \mathrm{C}$. It is practically insoluble in water, soluble in methanol, freely soluble in oil and glyceryl mono-oleate. It is used to delay or prevent oxidative rancidity of fats and oils.

Butylated hydroxytoluene: Butylated hydroxytoluene is used as an antioxidant in cosmetics, foods, and pharmaceuticals having melting point $70^{\circ} \mathrm{C}$. It is freely soluble in fixed oils and mineral oil and more soluble than butylated hydroxyanisole. It is mainly used to delay or prevent the oxidative rancidity of fats and oils. ${ }^{36}$

Citric acid: Citric acid exist as either monohydrate or anhydrous material and used in pharmaceutical formulations and food products as an acidifying agent, antioxidant, buffering agent, chelating agent and preservative having melting point $100^{\circ} \mathrm{C}$ (softens at $75^{\circ} \mathrm{C}$ )..$^{38}$

Meglumine: Meglumine is 1-deoxy-1-(methylamino)-Dglucitol. Meglumine is used as a pH-adjusting agent and solubilizing agent having melting point $100^{\circ} \mathrm{C}$ (softens at $\left.75^{\circ} \mathrm{C}\right) .39$

Polyethylene glycol (PEG): Depending upon the average molecular weight, PEGs are available in various grades i.e. liquid, semisolid and solid. They are available in grades and vary their physical properties. They have a slight but characteristic odour and a bitter taste. They are used as solubilizer and as thermal carrier in hot-melt technology. 40

\section{Equipment for Hot Melt Technology}

The hot-melt process involve melting of required excipients, raising their temperature slightly above their melting point with constant stirring at the constant temperature followed by spraying, congealing or coating etc. The process conditions and equipment for hot-melt process has been published by Jones and Percel. ${ }^{15}$ Various types of equipment can be used for the hot-melt processes such as fluid bed coater, turbo jet and conventional solid pan. The latter requires material holding tank for melting of the lipid and facility to keep it in molten and sprayable state throughout the process.

The material holding tank jacketed with electric heater having pneumatic stirrer is used to melt material under controlled temperature and stirring. The butterfly valve 6 is kept closed that allows the molten mass to circulate from tank through valve 4 and 5 using centrifugal monoblock or peristaltic pump and then back in tank. The process is continued until all tubings get equilibrated with desired temperature. Once the temperature is reached, valve 4 is closed and material is allowed to go back into the tank. The speed of pump is adjusted according to requirement, valve 5 is closed and valve 4 and 6 are opened and thus the molten material is circulated through valve 6 to spray the molten material without compromising the clogging of tubes and spray nozzle. The spray nozzle can be equipped with top, bottom and tangential spray fluid-bed coater. Thus, top spray method is used to prepare granules, spray congealed microparticles and pellets while bottom spray is used to coat the pellets by hot-melt process. 


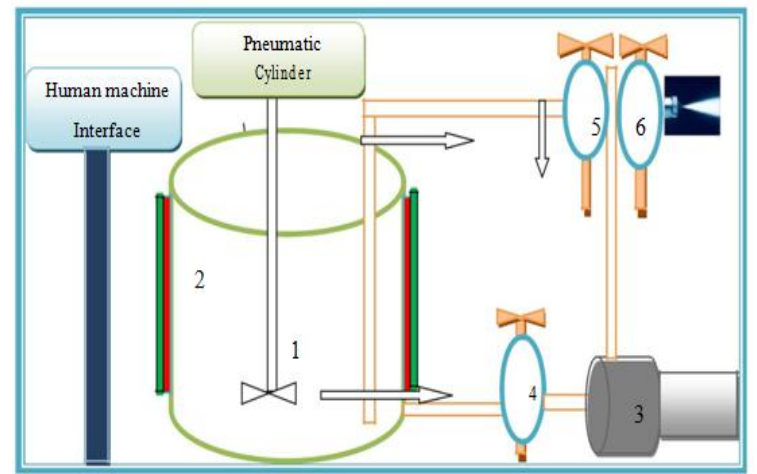

Table 1: Description of Material Holding Tank

Figure 1: Material holding tank equipped with facility for spray congealing.

Table 2: Equipment's used in the Preparation of Drug ER MUPS

\begin{tabular}{|l|l|l|}
\hline S.N. & Equipment & Purpose \\
\hline 1 & $\begin{array}{l}\text { Material holding tank equipped with facility for spraying } \\
\text { molten mass }\end{array}$ & $\begin{array}{l}\text { To melt the lipid and maintain temperature during } \\
\text { processing }\end{array}$ \\
\hline 2 & Fluid bed equipment (top spray and bottom spray) & To spray congeal the granules and its coating \\
\hline 3 & Vibratory sifter and sieves of various sizes & Sieving and grading of granules \\
\hline 4 & Octagonal blender & Blending \\
\hline 5 & Tablet press (Cadmach) & Compression of tablets \\
\hline
\end{tabular}

\section{Method of Preparation of Extended- Release MUPS}

Design of extended-release MUPS involved three steps -

1. Design, composition and preparation of Drug spray congealed matrix pellets.

2. Design and composition of top coating on Drug spray congealed matrix pellets.

3. Design, composition and compaction of Drug extendedrelease pellets into extended-release MUPS.

\section{Evaluation of Extended- Release MUPS}

Photomicrography of Extended-Release Pellets and MUPS: Magnified photographs of spray congealed pellets of various designed formulation prototypes were taken using digital microscope Intelplay QX3 attached to a personal computer. The photographs were used to examine the sphericity and smoothness, imperfections on the surface.

Evaluation of Physical Parameters of MUPS: Extendedrelease MUPS tablets were evaluated for physical parameters such as mechanical strength (unofficial tests) and friability ${ }^{34}$, 39 and disintegration time ${ }^{40}$. Test for uniformity of tablet weight was not done since the batch size was small.

In Vitro Dissolution Studies of Extended-Release Pellets and its MUPS: Dissolution tests were performed in accordance with USP $32-\mathrm{NF} 27$ and using apparatus 2 (paddle). ${ }^{39-54}$

Analysis of Content in Prepared Formulations: The reagents and procedure for determining, drug release and drug content in spray congealed extended-release pellets, top coated extended-release pellets and MUPS were according to USP32-NF27.43-49

\begin{tabular}{|l|l|}
\hline S.N. & Components of Material holding tank \\
\hline $\mathbf{1}$ & Material holding tank \\
\hline 2 & Pneumatic stirrer \\
\hline 3 & Centrifugal monoblock / peristaltic pump \\
\hline 4 & Butterfly valve \\
\hline 5 & Electric heating band \\
\hline 6 & Tank insulation \\
\hline 7 & \begin{tabular}{l} 
Interconnecting piping with triclover sanitary fitting \\
\hline
\end{tabular} \\
\hline
\end{tabular}


Table 3: In Vitro Dissolution Parameters for ER Pellets and MUPS of as per USP.

\begin{tabular}{|l|l|}
\hline Dissolution Parameters & Settings/Requirements \\
\hline USP dissolution test & In USP32-NF27 monograph for Extended Release Tablet \\
\hline Apparatus type & USP type 2 (paddle) \\
\hline Speed & 50 rpm \\
\hline Dissolution media & pH 6.8 phosphate buffer, $500 \mathrm{ml}$ \\
\hline Temperature of media & $37^{\circ} \mathrm{C} \pm 0.5^{\circ} \mathrm{C}$ \\
\hline Sampling time points & $1,4,8$ and 20 hours \\
\hline
\end{tabular}

Stability Studies on ER MUPS: MUPS samples of optimized batch were packaged in alu-alu blisters and stored under accelerated conditions $\left(40^{\circ} \mathrm{C} \text { and } 75 \% \mathrm{RH}\right)^{44-51}$ for three months. After three months, the tablets were subjected to evaluation of disintegration time, in vitro dissolution and drug content which were then collectively analysed to evaluate the quality of extended-release MUPS prepared with produced pellets.

\section{Advantages of MUPS over Conventional Modified- Release Formulations}

The various advantages of compacted MUPS over conventional modified-release tablets and/or multiparticulates filled capsules are as under -

\section{Pharmacokinetic advantages ${ }^{2,38-51}$}

$\checkmark \quad$ Rapid but uniform transit of micro pellets contained in MUPS from the stomach into small intestine, owing to their small size, and thus lesser possibility of localized irritation, better and more uniform drug absorption and greater bioavailability.

$\checkmark$ Uniform emptying of micropellets from stomach into small intestine facilitates rapid dissolution of enteric coating and drug release resulting in early $t_{\max }$ and $\mathrm{C}_{\max }$ (peak time and peak plasma concentration) in case of delayed-release formulations. In case of controlledrelease preparations, drug release is more uniform and possibility of dose dumping is avoided with minimized tendency for inter-subject variations.

\section{Pharmacodynamics advantages ${ }^{46-54}$}

$\checkmark$ Owing to rapid and uniform gastric emptying and subsequently uniform drug dissolution of pellets in the gastrointestinal tract due to their small size and larger surface, uniform drug absorption is facilitated which results in consistent and controlled pharmacological action.

$\checkmark \quad$ A further reduction in inter-and intra-subject variability in drug absorption and clinical response is facilitated since the number of pellets per MUPS dosage form is much more than a conventional pellet-filled capsule and possibility of dose dumping (in stomach) and/or incomplete drug release is further minimized.

$\checkmark \quad$ Reduces local irritation to gastrointestinal mucosa as the drug available in multiple units which disperse better in the gastrointestinal tract.

\section{Patient friendly dosage form ${ }^{48-52}$}

$\checkmark$ Mouth disintegrating MUPS dosage form having a palatable taste is suitable for paediatric and geriatric patients who cannot swallow tablet or capsule, e.g. Prevacid ${ }^{\circledR}$ SoluTab. It can also be administered via nasogastric tube ( $\geq 8$ French).

$\checkmark$ The orodispersible MUPS medication can be taken without water, especially while travelling since the dosage form can be designed as orally disintegrating preparation that contains flavours and sweeteners that stimulate salivation and swallowing e.g. Prevacid ${ }^{\circledR}$ SoluTab.

$\checkmark \quad$ Being tablets, quite unlike a capsule formulation, MUPS can be also designed into a divisible dosage form, without compromising the drug release characteristics of coated particles contained therein. e.g. Toprol-Xl ${ }^{\circledR}$ (Metoprolol Succinate Extended-Release Tablets)

$\checkmark$ The MUPS have lesser tendency of adhering to oesophagus during swallowing.

$\checkmark$ Smaller volume/size of tablet leads to better patient compliance than capsules.

\section{Processing advantages ${ }^{53}$}

$\checkmark \quad$ Greater physicochemical and microbiological stability of pellets owing to their embedment in inert matrix.

$\checkmark \quad$ Rapidity of processing in comparison to capsules using existing tableting facility. ${ }^{52}$

$\checkmark \quad$ Lower cost of processing owing to higher processing speed, elimination of capsule cost, etc.

$\checkmark \quad$ The product is relatively tamper-proof.

$\checkmark$ Unlike conventional tablets, there is reduction in dust problems during compression.

$\checkmark \quad$ Pellets intended for compaction into MUPS demonstrate excellent flow properties owing to their near spherical nature and thus easy to process into a tablet as compared to conventional granules used for tableting. Such compositions also require lesser amount of lubricants for tablet processing.

\section{Regulatory advantages}

$\checkmark \quad$ Extension of patent life.

$\checkmark \quad$ Line extension of product.

$\checkmark$ Possibility of patenting and registering the product in various markets globally.

\section{CONCLUSION}

Hot-melt technology is used to design variety of oral dosages forms such as tablets with improved bioavailability of poorly water soluble drugs, taste masking and, MUPS and multiple unit formulations. Hot-melt technology is used to design different dosages forms and drug delivery systems which fulfill the therapeutic needs of the patient, which are costeffective and manufactured by eco-friendly process. Hot-melt technology is used to enhance the bioavailability of poorly water soluble and lipophilic drugs, taste masking of bitter drugs, fabrication of extended release multiparticulates and designing of micropellets for compaction. 


\section{REFERENCES}

1. Dixit N, Maurya SD, Sagar BPS, Sustained release drug delivery system, Indian Journal of Research in Pharmacy and Biotechnology, 2013; 1(3):305-310.

2. El-Egakey MA, Soliva M, Speiser P, Hot extruded dosage forms Technology and dissolution kinetics of polymeric matrices, Pharm Acta Helv, 1971; 46(1):31-52.

3. Dreiblatt A, Process design. In: Ghebre-Sellassie I, Martin C, editors. Pharmaceutical extrusion technology, New York: Marce Dekker, Inc, 2003; 153-169.

4. McGinity JW, Zhang F, Koleng J, Repka M, Hot-melt extrusion as a pharmaceutical process, Am Pharm Rev, 2001; 4:25-37.

5. Breitenbach J, Melt extrusion: from process to drug delivery technology, Europian Journal of Pharmaceutics and Biopharmaceutics, 2002; 54(2):107-17.

6. Shah S, Repka MA, Melt extrusion in drug delivery: three decades of progress. Melt extrusion. New York: Springer; 2013; 3-46.

7. Crowley MM, Zhang F, Repka MA, Thumma S, Upadhye SB, Battu SK, Pharmaceutical applications of hot-melt extrusion: part I. Drug Development and Industrial Pharmacy, 2007; 33(9):90926.

8. Repka MA, Battu SK, Upadhye SB, Thumma S, Crowley MM Zhang F, Pharmaceutical applications of hot-melt extrusion: part II. Drug Development and Industrial Pharmacy, 2007 33(10):1043-57.

9. Patil H, Kulkarni V, Majumdar S, Repka MA, Continuous manufacturing of solid lipid nanoparticles by hot melt extrusion, International Journal of Pharmaceutics, 2014; 471(12):153-6.

10. Repka MA, Majumdar S, Kumar Battu S, Srirangam R, Upadhye SB, Applications of hot-melt extrusion for drug delivery. Expert Opin Drug Deliv., 2008; 5(12):1357-76

11. Repka MA, Shah S, Lu J, Maddineni S, Morott J, Patwardhan K, Melt extrusion: process to product. Expert Opin Drug Deliv, 2012; 9(1):105-25.

12. Shah S, Maddineni S, Lu J, Repka MA, Melt extrusion with poorly soluble drugs. International Journal of Pharmaceutics, 2013; 453(1):233-52.

13. Patil H, Tiwari RV, Upadhye SB, Vladyka RS, Repka MA Formulation and development of $\mathrm{pH}$-independent/dependent sustained release matrix tablets of ondansetron $\mathrm{HCl}$ by a continuous twin-screw melt granulation process. International Journal of Pharmaceutics, 2015; 532):237-54

14. Kleinebudde $\mathrm{P}$, Lindner $\mathrm{H}$. Experiments with an instrumented twin-screw extruder using a single-step granulation/extrusion process. International Journal of Pharmaceutics, 1993; 94(1):49-58

15. Gursoy RN, Benita S, Self-emulsifying drug delivery systems (SEDDS) for improved oral delivery of lipophilic drugs, Biomed Pharmacother., 2004; 58, 173-182.

16. Pouton CW, Lipid formulation for oral administration of drugs: non emulsifying, self-emulsifying and 'self-microemulsifying' drug delivery systems, Eur. J. Pharm. Sci., 2000; 11(2)S93-S98.

17. Wilson M, Williams MA, Jones DS, Andrews GP, Hot-melt extrusion technology and pharmaceutical application. Ther Deliv., 2012; 3(6):787-97.

18. Maurya SD, Prajapati SK, Gupta AK, Saxena GK, Dhakar RC Formulation and Evaluation of Ethosomal Drug Delivery System of Stavudine, Indian Journal of Pharmaceutical Education and Research, 2010; 44(1):102-108.

19. Stevens M, Covas J, Extrusion, principles and operation, London: Chapman \& Hall; 1995. pp. 270-295.

20. Mollan M, Historical overview. In: Ghebre-Sellassie I, Martin C editors. Pharmaceutical extrusion technology. New York: Marcel Dekker, Inc; 2003. pp. 1-18.

21. Thiele W. Twin-screw extrusion and screw design. In: GhebreSellassie I, Martin C, editors. Pharmaceutical extrusion technology. New York: Marcel Dekker, Inc; 2003. pp. 69-98.

22. Wang $\mathrm{Y}$, Compounding in co-rotating twin-screw extruders. Shrewsbury UK: Smithers RAPRA; Report 116, 2000. p. 3.

23. Loukus JE, Halonen A, Gupta M. Elongational flow in multiple screw extruders. ANTEC-Conference Proceeding. 2004; 1:133137.

24. Luker K, Single-screw extrusion and screw design. In: GhebreSellassie I, Martin C, editors. Pharmaceutical extrusion technology. New York: Marcel Dekker, Inc; 2003. pp. 39-68.
25. Chokshi R, Zia H, Hot-melt extrusion technique: a review. Iran J Pharm Res, 2010; 3:3-16.

26. Nakamichi K, Yasuura H, Kukui H, Oka M, Izumi S, Andou T, New preparation method of solid dispersion by twin screw extruder. Pharm Technol Jpn. 1996; 12:715-29.

27. Douroumis D. Taste masking using hot-melt extrusion. In: Douroumis D, Hot-melt extrusion: pharmaceutical application. 1. UK: John Wiley \& Sons, Ltd; 2012. pp. 201-221.

28. Gogos CG, Liu H, Wang P, Laminar dispersive and distributive mixing with dissolution and applications to hot-melt extrusion. In: Douroumis D, Hot-melt extrusion: pharmaceutical applications. UK: John Wiley \& Sons, Ltd; 2012. pp. 261-84.

29. Dreiblatt A, Technological considerations related to scale-up of hot-melt extrusion processes. In: Douroumis D, Hot-melt extrusion: pharmaceutical application, UK: John Wiley \& Sons, Ltd; 2012. pp. 285-300.

30. Perdikoulias J, Dobbie T. Die design. In: Ghebre-Sellassie I, Martin C, editors. Pharmaceutical extrusion technology. New York: Marcel Dekker, Inc; 2003. pp. 99-109.

31. Yajima T, Umeki N, Itai S, Optimum spray congealing conditions for masking the bitter taste of clarithromycin in wax matrix, Chem. Pharm. Bull., 1999; 47(2):220-225.

32. Vergote GJ, Kiekens F, Vervaet C, Remon JP, Wax beads as cushioning agents during the compression of coated diltiazem pellets, Eur. J. Pharm. Sci., 2002; 17(3):145-151.

33. Maurya SD, Tilak VK, Dhakar RC, Verma KK, Soni U, Gupta, Preparation and evaluation of floating tablet of famotidine through solid dispersion, International Journal of Contemporary Research and Review, 2011; (2)1:21-30.

34. Achanta S, Adusumilli PS, James KW, Rhodes CT, Development of hot-melt coating methods, Drug Development and Industrial Pharmacy, 1997; 23(5), 441-449.

35. Maschke A, Becker C, Eyrich D, Kiermaier J,, Blunk T, Gopferich A, Development of a spray congealing process for the preparation of insulin-loaded lipid microparticle and characterization thereof, Eur. J. Pharm. Biopharm., 2007; 65:175-187.

36. Dhakar RC, Maurya SD, Aggrawal S, Kumar G, Tilak VK, Design and evaluation of SRM microspheres of Metformin hydrochloride, Pharmacie Globale (IJCP), 2010; 1(07): 1-6.

37. Battu SK, McGinity JW, Martin C, Pharmaceutical application of hot-melt extrusion: Part I. Drug Dev. Ind. Pharm., 2007; 33:909926.

38. Kidokoro M, Haramiishi Y, Sagasaki S, Shimizu T, Yamamoto Y Application of fluidized hot-melt granulation (FHMG) for the preparation of granules for tableting: properties of granules and tablets prepared by FHMG, Drug Dev. Ind. Pharm., 2002; 28(1):67-76.

39. Dhakar RC, Maurya SD, Sagar BPS, Prajapati SK, Jain CP, Variables influencing the drug entrapment efficiency of microspheres: a pharmaceutical review, Der Pharmacia Lettre, 2010, 2(5):102-116.

40. Sinchaipanid, N., Junyaprasert, V., Mitrevej, A., Application of hot melt coating for controlled release of propranolol hydrochloride pellets, Powder Technol., 2004; 141(3):203-209.

41. Patel M, Patel S, Patel N, Patel M, A review of novel oral lipid Ora based formulation for poorly soluble drugs, Int. J. Pharm. Sci. Nanotech., 2011; 3(4):1182-1192.

42. Dhakar RC, Maurya SD, Dangi G, Kumar G, Gupta M, Kiroriwal S, Buccal Adhesive Dosage Forms As A NISDD: A Pharmaceutical Review, Res Pharmaceutica, 2010; 1(1):46-59.

43. Sohi H, Sultana Y, Khar RK, Taste masking technologies in oral pharmaceuticals: recent developments and approaches, Drug Dev. Ind. Pharm., 2004; 30(5), 429-448.

44. Abdul, S, Chandewar AV, Jaiswal SB, A flexible technology for modified-release drugs: Multiple-unit pellet system (MUPS), Journal of Controlled Release, 2010; 147(1):2-16.

45. Maurya SD, Rawal RK, Jha S, Chauhan PS, Kumar A, Drug Loaded Beads: Current Status, American Journal of PharmTech Research, 2013; 3(1):331-337

46. Kidokoro M, Haramiishi Y., Sagasaki S, Shimizu T, Yamamoto Y, Application of fluidized hot-melt granulation (FHMG) for the preparation of granules for tableting: properties of granules and tablets prepared by FHMG, Drug Dev. Ind. Pharm., 2002; 28(1):67-76.

47. Coleman RA, Lee DP, Enzymes of triglyceride synthesis and their regulation, Progress in Lipid Research, 2004; 43(2):134-176 
48. Lechter CS, Waxes In: Kirk-Othmer, Encyclopedia of Chemical Technology, John Wiley and Sons, New York, 1984, 24:466-481.

49. Metoprolol Succinate Extended Release Tablets, USP32-NF27, vol. 3, The United States Pharmacopeial Convention, USA, 2009 2965.

50. Jones DM, Percel PJ, Coating of multiparticulates using molten materials. Ghebre Sellassie, I., Multiparticulate Oral Drug Delivery, Marcel Dekker, New York, 1994, 113-142.

51. Sherrington PJ, Oliver $\mathrm{R}$, Compaction and other granulation methods. In: Goldberg, A. S., Granulation, Hayden, London, Philadelphia, 1981, 141-152.
52. Ghebre-Sellassie I, Pellets - A general overview, Pharmaceutical Pelletization Technology, Marcel Dekker Inc., New York, 1989, 2.

53. Kottke MK, Rudnic EM, Tablet dosage forms. In: Banker, G.S., Rhodes C.T., Modern Pharmaceutics, Marcel Dekker Inc., NY, 2002; 2nd edition, 280-326.

54. Disintegration USP32-NF27, vol. 1, The United States Pharmacopeial Convention, USA, 2009, 262-263. 